\title{
E Sacroiliac Joint Ligaments and Sacroiliac Pain: A Case-Control Study on Micro- and Ultrastructural Findings on Morphologic Alterations
}

Niels Hammer, MD ${ }^{1-4}$, Benjamin Ondruschka, MD, and Volker Fuchs, MD

From: ${ }^{1}$ Department of Anatomy, Medical University of Graz, Graz, Austria; '2Department of Anatomy, University of Otago, Dunedin, New Zealand; ${ }^{3}$ Department of Trauma, Orthopedic and Plastic Surgery, University Hospital of Leipzig, Leipzig, Germany; ${ }^{4}$ Fraunhofer Institute for Machine Tools and Forming Technology, Dresden, Germany; ${ }^{\text {Institute of }}$ Legal Medicine, Medical Faculty University of Leipzig, Leipzig, Germany; ${ }^{6}$ Department of Orthopedics, AMEOS Hospital, Halberstadt, Germany

Address Correspondence: Niels Hammer, MD Department of Macroscopic and

Clinical Anatomy University of Graz Harrachgasse 21, 8010 Graz, Austria E-mail: nlshammer@googlemail.com niels.hammer@medunigraz.at

Disclaimer: There was no external funding in the preparation of this manuscript.

Conflict of interest: Each author certifies that he or she, or a member of his or her immediate family, has no commercial association (i.e., consultancies, stock ownership, equity interest, patent/licensing arrangements, etc.) that might pose a conflict of

interest in connection with the submitted manuscript.

Manuscript received: 12-11-2018 Revised manuscript received: 04-04-2019 Accepted for publication: 04-18-2019

Free full manuscript: www.painphysicianjournal.com
Background: The sacroiliac joint (SIJ) is a common source of low back pain. SIJ pain has shown to have negative impact on patients' quality of life. Although clinically there is an increasing interest to treat SIJ-related pain both conservatively and surgically, the underlying mechanisms related to pathology in that region are poorly understood. One hypothesis is that the SIJ ligaments are structurally altered in SIJ pain.

Objectives: The given study investigated patient cases with different pain durations undergoing posterior distraction arthrodesis of the SIJ, with subsequent micro- and ultrastructural assessment of the interosseous and posterior SIJ ligaments compared with autopsy controls without known history of low back pain.

Study Design: Case-control study. Morphologic-pathological analysis of tissue samples obtained during surgery with controls from legal medicine.

Setting: Rural hospital setting in Halberstadt, Germany.

Methods: SIJ ligaments were removed from 6 patients undergoing SIJ arthrodesis for histological and ultrastructural assessment in scanning and transmission electron microscopy, and compared with 6 controls without known history of SIJ pathology.

Results: A number of alterations were observed in the ligaments of patients with SIJ, namely ligament disruption, collagen loosening and coiling, vascularization, and hemorrhage. In some areas, these changes were observed in proximity to healthy (structurally unaltered and intact tissues), indicative of a potential disease progression. Comparison to controls yielded a significant correlation between SIJ pathology and the level of collagen degeneration $(\phi \geq$ $0.82 ; P<0.001)$

Limitations: Small sample size, method of tissue removal from patients may have influenced tissue integrity.

Conclusions: The combined clinical, histological, and ultrastructural analysis provided, to our knowledge, first-time evidence of morphologic SIJ ligament alteration of a nontraumatic and noninflammatory cause. Further research is necessary to elucidate these structural changes and to substantiate pain duration and patient-history-dependent changes at the ligaments of the posterior pelvis.

Key words: Collagen, electron microscopy, histological and ultrastructural assessment, interosseous sacroiliac ligament, low back pain, sacroiliac joint

Pain Physician 2019; 22:E615-E625 
T he sacroiliac joint (SIJ) is a common source of low back pain (1-5). A variety of novel treatment strategies have emerged over the last few decades, especially for surgical fusion (6-10) or denervation (11-14) of the SIJ. To date, despite the joint being appreciated as an important site of assumed pathology (15), little is known about the potential mechanisms of pain generation. Four potential mechanisms leading to SIJ pain have been hypothesized for the joint, namely traumatic bone and ligament injury, inflammation, alterations in muscle function and morphology, and neuropathy of the supplying nerves $(15,16)$.

An identification of such alterations on a morphologic basis has, to date, been unsuccessful with the exception of seronegative spondyloarthropathy (17-21) and traumatic bone or ligament disruption (22-24). Existing studies have so far failed to identify morphologic alterations directly related to chronic SIJ pain (25). Age- and posture-related changes in the joint have repeatedly been shown to be physiological adaptations to enhance form and force closure (26-31), being mediated via the bony ridges and grooves (32-35), the dense ligaments, and also the muscles stabilizing the joint actively $(30,31,36,37)$.

One hypothesis related to SIJ pathology is that its ligaments are altered regarding morphology or composition, to the effect that load distribution throughout the joint becomes altered with pain being causative or an effect. Given the introduction of new surgical techniques aiming to stabilize or even fully fuse the SIJ (610), further research becomes necessary to clearly identify any pathology. To date, only one surgical technique uses a posterior approach to the SIJ and the interosseous and posterior ligaments $(8,38)$, making it possible to assess their morphology following operative ligament removal to place an implant at the side, called distraction interference arthrodesis.

Tissues obtained from patients undergoing SIJ fusion with this technique allow for the unique chance to assess the SIJ ligaments of patients with chronic SIJ pain histologically and ultrastructurally. The aim of this given case-control study was to show specific changes present in the SIJ ligaments in cases of patients with chronic low back pain. It could be shown that in patients with SIJ pain ligament failure is observed, accompanied by hemorrhage and collagen disarrangement.

\section{Methods}

SIJ ligament tissue samples were obtained from 6 patients undergoing SIJ fusion using the posterior distraction arthrodesis technique in the time frame 2016 to 2018 at a rural hospital setting in Halberstadt, Germany (all women, mean age $57.8 \pm 9.5$ years). All of these patients were diagnostically confirmed cases of SIJ-related pain. For comparison, age-matched SIJ ligament tissue samples were obtained bilaterally from 6 cadavers from legal medicine during autopsy with no previous history or autoptic signs of musculoskeletal disease (bilateral samples of 3 women and 3 men, mean age $57.3 \pm 10.4$ years). Ethical approval was obtained from the ethics committee of the University of Leipzig (301/18-ek).

\section{Surgical Technique}

With the patient in prone position, a midline approach was used at the level of the upper border of the sacrum followed by a lengthwise incision of the thoracolumbar fascia close to the posterior superior iliac spine. The posterior and interosseous SIJ ligaments were subsequently exposed at the \$1-S2 level, as described elsewhere (8). As part of the surgical procedure, these ligaments were removed within the recess formed between the posterolateral aspect of the sacrum and the corresponding cortical surface of the ilium. The tissue samples used for histology and electron microscopy were removed sharply to rule out any damage induced by blunt manipulation, resulting in collagen disintegration. The required DIANA implant (Signus Medizintechnik, Alzenau, Germany) was then inserted over a guidewire positioned along the weight-bearing axis of the ilium. The recess and the implant were subsequently filled completely with homologous cancellous bone. Samples were obtained from the controls in a similar manner and by the same team of experienced SIJ interventionists during back and pelvis preparation at forensic autopsies to guarantee for comparability, and all tissues were removed with extreme care not to cause iatrogenic injury.

\section{Histology and Electron Microscopy}

Representative samples of the removed ligaments were immediately fixed in $3 \%$ glutaraldehyde/0.1 M phosphate buffer ( $\mathrm{pH}=7.4)$. Tissues for histology were postfixed in $3 \%$ paraformaldehyde, paraffin-embedded and sectioned at $10 \mu \mathrm{m}$. Hematoxylin-eosin (HE) and Giemsa staining was carried out as routine staining meth- 
ods. Further subsamples for electron microscopy were washed in distilled water and dehydrated, followed by the critical point drying process (CPD-030, Bal-Tec AG, Liechtenstein). Scanning electron microscopy (SEM) was conducted using a JSM-6700F field emission microscope (JEOL Ltd., Tokyo, Japan) at magnifications ranging from 2,500x to 33,000x. Transmission electron microscopy (TEM) samples were processed as shown previously (39). A Philips CM100 BioTWIN (Philips/FEI Corporation, Eindhoven, the Netherlands) equipped with a MegaView III digital camera (Olympus Soft Imaging Solutions GmbH, Münster, Germany) was used to obtain TEM images at magnifications between 9,700x and 33,000x. All tissues were assessed in a blinded manner to minimize the bias of the rater.

\section{Statistical Evaluation}

The statistical comparisons between both groups (SIJ patients vs. control group, and women only in both groups) were performed using Microsoft Excel (Microsoft Corporation, Redmond, WA) and SPSS Version 24 (IBM Corporation, Armonk, NY). Cramér's $\phi$ correlations were determined following the chi-square test to compare the collagen matrix integrity in SEM between the samples from patients with SIJ and controls. For this purpose, 5 fields of vision were assessed at magnifications of 2,500x and 20,000x for a semiquantitative classification of collagen integrity. Fields with no collagen damage were classified as "fully intact," fields with damaged fibers as "partial rupture," and fields with fiber bundle or multiple fiber damage as "fully disrupted" according to the classification shown elsewhere (40). $P$ values of $\leq$ 0.05 were considered as statistically significant.

\section{ResUlts}

In the patient cohort with SIJ pain presented here, none had any major trauma related to their SIJ pathology. One of the 6 women in the SIJ pain group was nulliparous, one uni-, and 4 multiparous. Two of the 3 women in the control group were multiparous and one nulliparous. The diagnostic algorithm included at least 3 positive tests for SIJ pain included Mennell sign, FABER test, distraction test, compression test, thigh thrust test, sacral thrust test, and sitting intolerance. None of the patients suffered from neurologic deficits prior to the surgery. Visual analog scale ratings on pain averaged $6.8 \pm 1.0$ prior to the surgery at rest, and $9.1 \pm$ 1.3 when physically active. Preoperative magnetic resonance imaging (MRI) and computed tomography (CT) typically showed no signs of traumatic injury, as depicted in Fig. 1. However, arthritis of the SIJ with vacuum phenomenon, joint narrowing, and subchondral sclerosis were observed commonly as radiologic changes. Surgical fusion of the SIJ was conducted using a 17- $\mathrm{mm}$ implant in one case and 19-mm implants in 4 cases, respectively. Postoperative x-ray and CT showed an exact positioning of the implant in all cases, as exemplified in Fig. 1.

\section{Histological and Ultrastructural Findings}

Both intact and undisturbed and altered regions were observed in the samples removed during surgery. Figure 2 illustrates microscopically intact ligaments of the SIJ obtained from healthy controls. The typical characteristics were parallel-aligned collagen bundles and intact tenocytes throughout these samples from the controls (Fig. 2A). Quantities of proteoglycan-rich regions were further observed, indicative of slight chondrification (Fig. 2B). The ultrastructural workup by SEM confirmed the parallel alignment of collagen bundles (Fig. 2C) and intact D-periods at further magnification, shown by the striated appearance (Fig. 2D).

The samples obtained from patients with SIJ pain showed a different picture compared with the healthy controls. Here, a variety of morphologic alterations were seen, indicative of disruptions in the ligament tissue (Figs. 3 and 4). Figure 3A gives an overview from one patient sample and includes cartilage as well as SIJ ligaments and a hematoma. The magnification of the HE-stained sample (Fig. 3B) shows intact collagens

Table 1. Evaluation of collagen integrity from SEM regarding collagen integrity. The total of $100.1 \%$ is the result of rounding.

\begin{tabular}{|c|c|c|c|c|}
\hline \multirow{2}{*}{ Sample Type } & \multicolumn{3}{|c|}{ Collagen Integrity } & \multirow{2}{*}{ Cramér's $\phi$} \\
\hline & Fully Intact & Partially Disrupted & Fully Disrupted & \\
\hline Control 2,500x $(n=60)$ & $71.7 \%$ & $26.7 \%$ & $1.7 \%$ & \multirow{2}{*}{$\begin{array}{c}\varphi=0.82 \\
P<0.001\end{array}$} \\
\hline SIJ pain 2,500x $(\mathrm{n}=30)$ & $0.0 \%$ & $53.3 \%$ & $46.7 \%$ & \\
\hline Control 20,000x $(n=60)$ & $46.7 \%$ & $51.7 \%$ & $1.7 \%$ & \multirow{2}{*}{$\begin{array}{c}\varphi=0.83 \\
P<0.001\end{array}$} \\
\hline SIJ pain $20,000 x(n=30)$ & $0.0 \%$ & $33.3 \%$ & $66.7 \%$ & \\
\hline
\end{tabular}




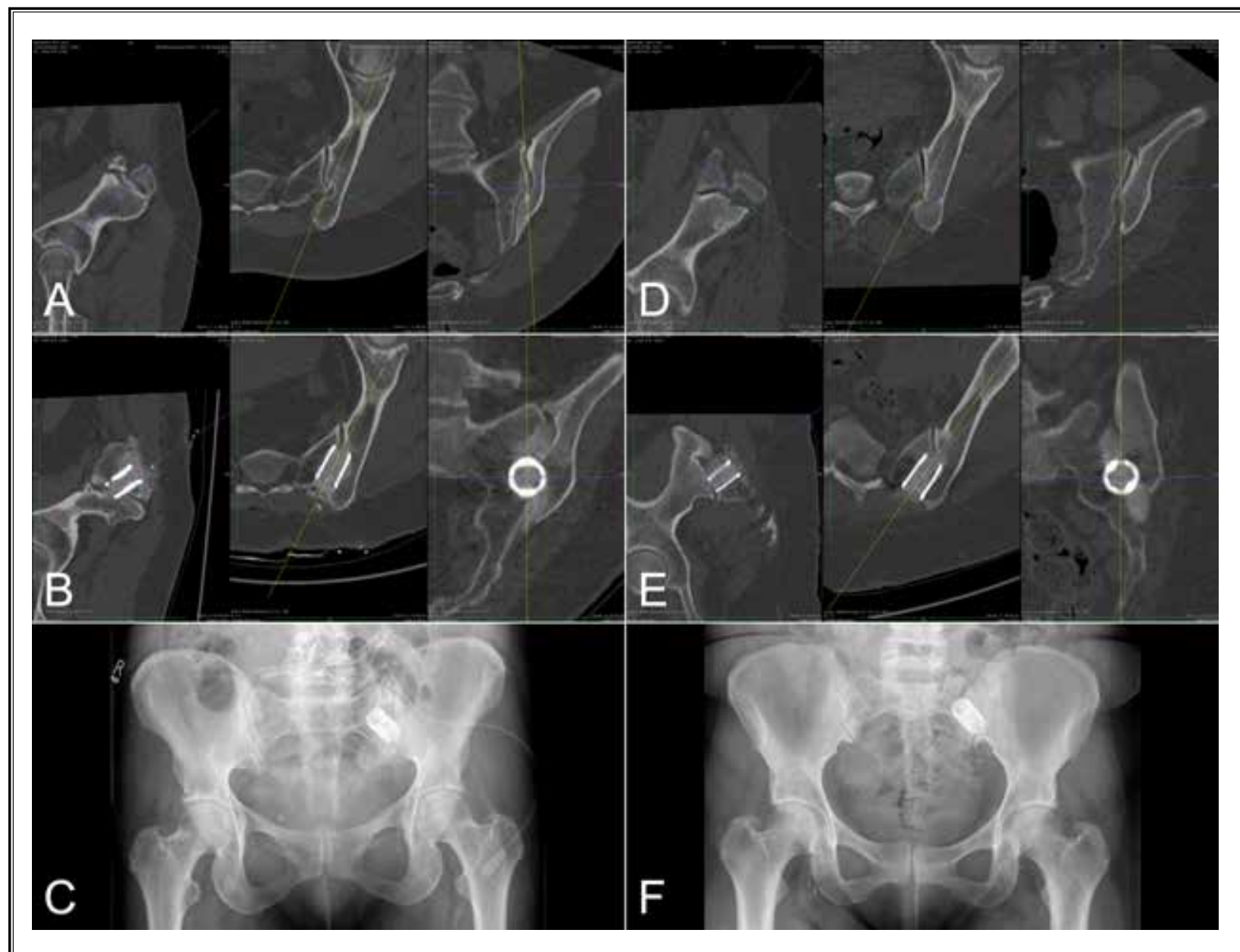

Fig. 1. Preclinical and postoperative CT of a woman aged 55 years prior to posterior distraction arthrodesis surgery (A), and postoperative $C T$ (B) and $x$-ray (C) imaging showing correct implant placement. (D-F) A second case is shown.

(note the bands in the tissue appearance in the top right corner), as well as disrupted collagens in the central part of the image, intermitted by a blood vessel. The Giemsa staining showed the extent of the collagen bundle disruption more visibly (Fig. 3 C and D). In SEM (Fig. $3 E$ and $F$ ), signs of collagen disruption were observed, showing both intact and unraveled collagens, partially with collagen bundle breakage. Figure 4 gives further examples of pathological alteration within the ligament tissue. The collagens of the sacroiliac ligaments were disrupted (note the loss of overall collagen orientation in the sample in Fig. 4A and B), and blood extravasation was seen outside of the vessels (perivascular) in the tissue. Giemsa staining (Fig. 4C and D) confirmed an undirected chondrification interspersing the collagens. The ultrastructural workup by SEM in Fig. $4 \mathrm{E}-\mathrm{G}$ showed further signs of degeneration, with an overall lumpy appearance (Fig. 4E and F), loss of collagen periodicity (Fig. 4F), and collagen balls indicative of mechanical failure of the collagens (Fig. 4G).

Further imaging provided by TEM is shown in Fig. 5 , resembling the findings from SEM. Regions with regular and dense collagen alignment and visible D-periods were observed in the controls (Fig. 5A and B), and in the samples from patients with SIJ pain, areas with loosened collagens and reduced collagen diameter (Fig. $5 C$ and D) and regions with kinked collagens (Fig. 5E and F).

Quantification of the findings from SEM revealed that a majority of collagens were fully or partially intact in the controls in both the 2,500x and 20,000x magnification (Table 1). In the samples from the patients with SIJ pain, a majority were partially or fully disrupted especially in higher magnifications. Full collagen damage 


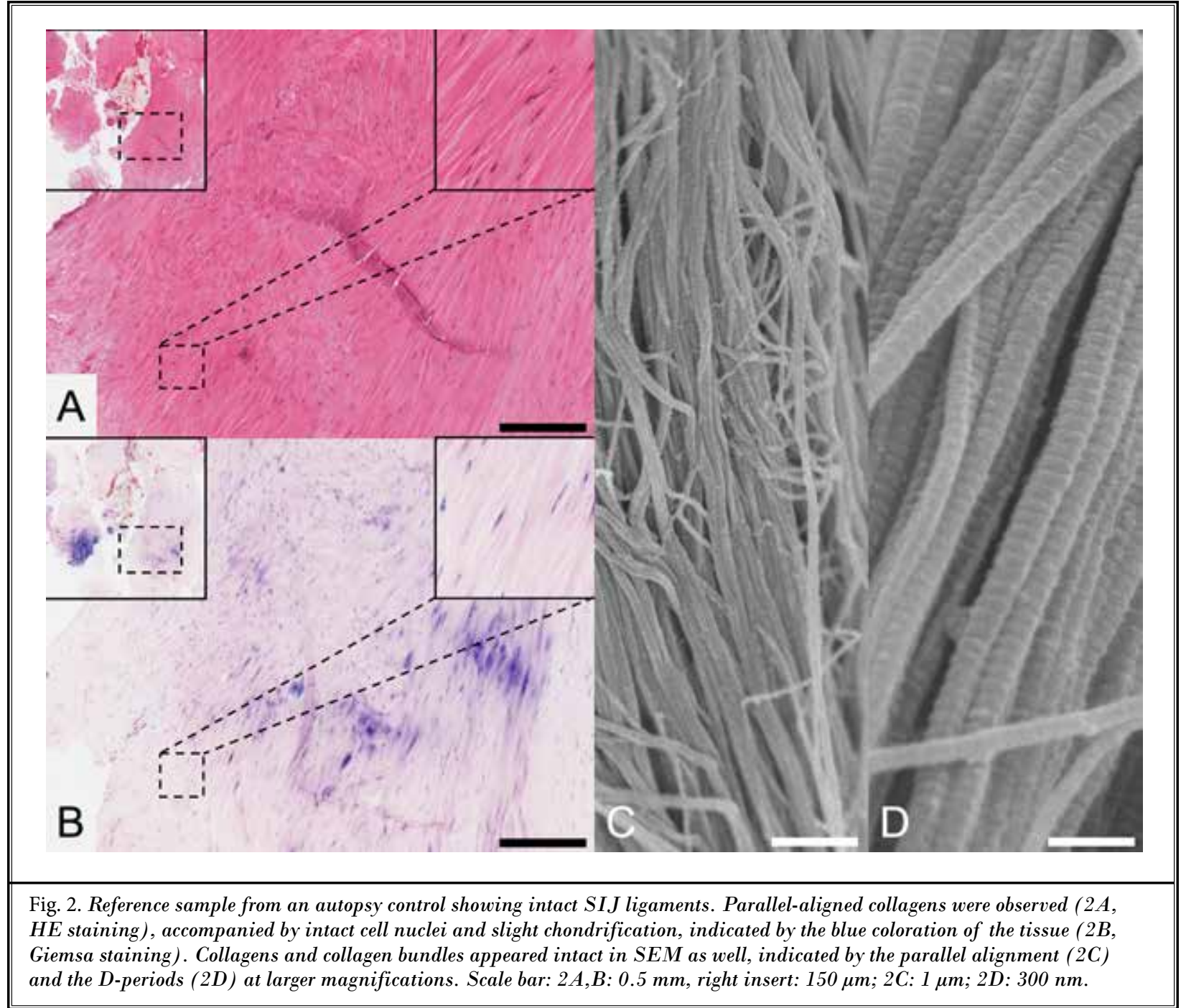

was observed more often in higher magnifications. Statistical comparison revealed that collagen integrity was significantly higher in controls than in patients with SIJ pain, with a strong association toward collagen damage in patients with SIJ $(\phi \geq 0.82)$. On a qualitative level, similar histological and ultrastructural findings were observed when comparing the findings in the SIJ pain group with the female controls separately. No relation was observed between numbers of pregnancies and ligament integrity.

\section{Discussion}

To our knowledge, this study for the first time provided morphologic evidence on the pathological changes that occur in the SIJ ligaments in patients with chronic SIJ pain. Although changes have previously been hypothesized as a cause or consequence for the SIJ, no histological or ultrastructural changes have, to date, been reported for the ligamentous soft tissues of the posterior pelvis as a consequence of nontraumatic and noninflammatory cause.

A variety of surgical techniques have evolved for treating the SIJ surgically in recent years $(6-9,41)$, complementing existent nonsurgical treatments $(25,42-44)$, fluoroscopy-or CT-guided injections (45-48), peripheral nerve stimulation $(49,50)$, and radiofrequency ablation (11-14). Although the efficacy of these surgical techniques is presently under discussion, but not in the scope of this research, one of these surgical techniques, the posterior distraction arthrodesis method, now al- 


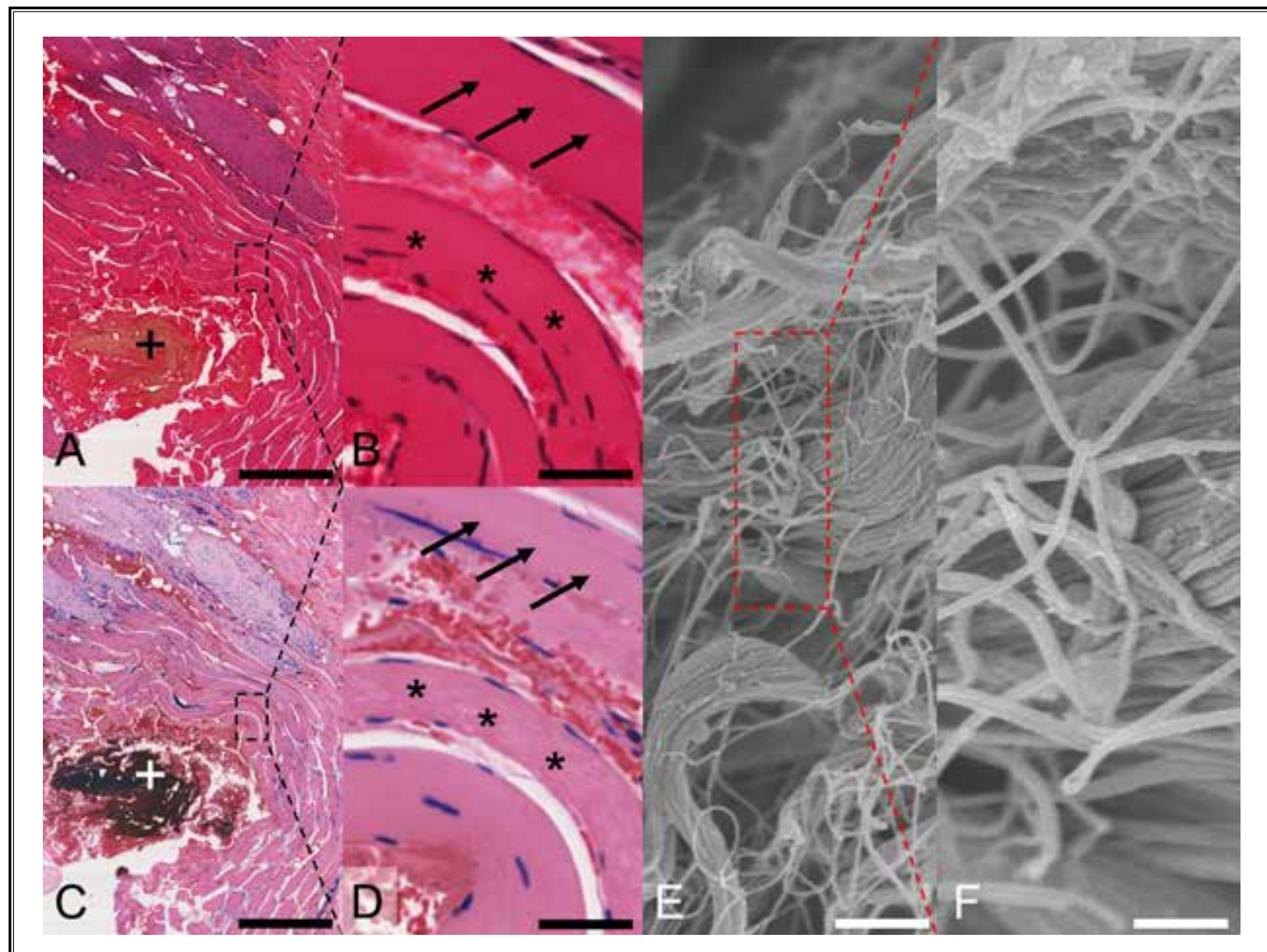

Fig. 3. Sample of SIJ tissue showing signs of collagen degeneration. Areas of intact collagens were observed in both the HEstained $(3 A, B)$ and the Giemsa-stained (3C,D) samples. Hemorrhage was seen in the tissue (marked with + ), potentially caused by mechanical disruption of one of the vessels seen in the images. Note the existence of both intact (arrows in $3 B, D$ ) and disrupted collagens (asterisks), indicated by the D-periods and their absence. In SEM, condensed and structurally altered collagens were seen (3E), as well as unraveled collagen fibers (3F). Scale bar: $3 A, C: 1 \mathrm{~mm} ; 3 B, D: 160 \mu \mathrm{m} ; 3 \mathrm{E}: 2.5 \mu \mathrm{m} ; 3 \mathrm{~F}$ : $400 \mathrm{~nm}$.

lows for the removal of parts of the SIJ ligaments as part of a SIJ fusion procedure. These tissues can be evaluated as part of a morphologic and pathological assessment. However, the SIJ ligaments thus far appear to be neglected regarding histological routine assessment.

Previous research indicated that alterations in joint morphology occur in the SIJ quite early in life as a consequence of upright posture to increase friction in the joint and to enhance load distribution from the spine and trunk to the pelvis and lower extremities $(26,28,29,33,51-53)$. Different subtypes of cartilage have been reported for the sacral and iliac joint surfaces with hyaline and fibrillary cartilage, with the latter showing an irregular network of thickened collagens, inhomogeneous appearance as a result of shearing forces (33). Furthermore, subchondral bone plates penetrated with blood vessels $(33,35,54)$ and diminished type 2 collagen immunoreactivity, as well as type 1 collagens at the joint surface (33), have been found at the SIJ surface, all indicators of osteoarthritis. In particular, type 1 cartilage does not normally exist in other healthy hyaline joints (33). It has been stated that such changes involve not only the cartilage but also the bone interface, namely with osteophytes, subchondral sclerosis, cartilage loosening, and the formation of grooves and ridges $(32-35,51)$. There is controversy if bony erosions, 


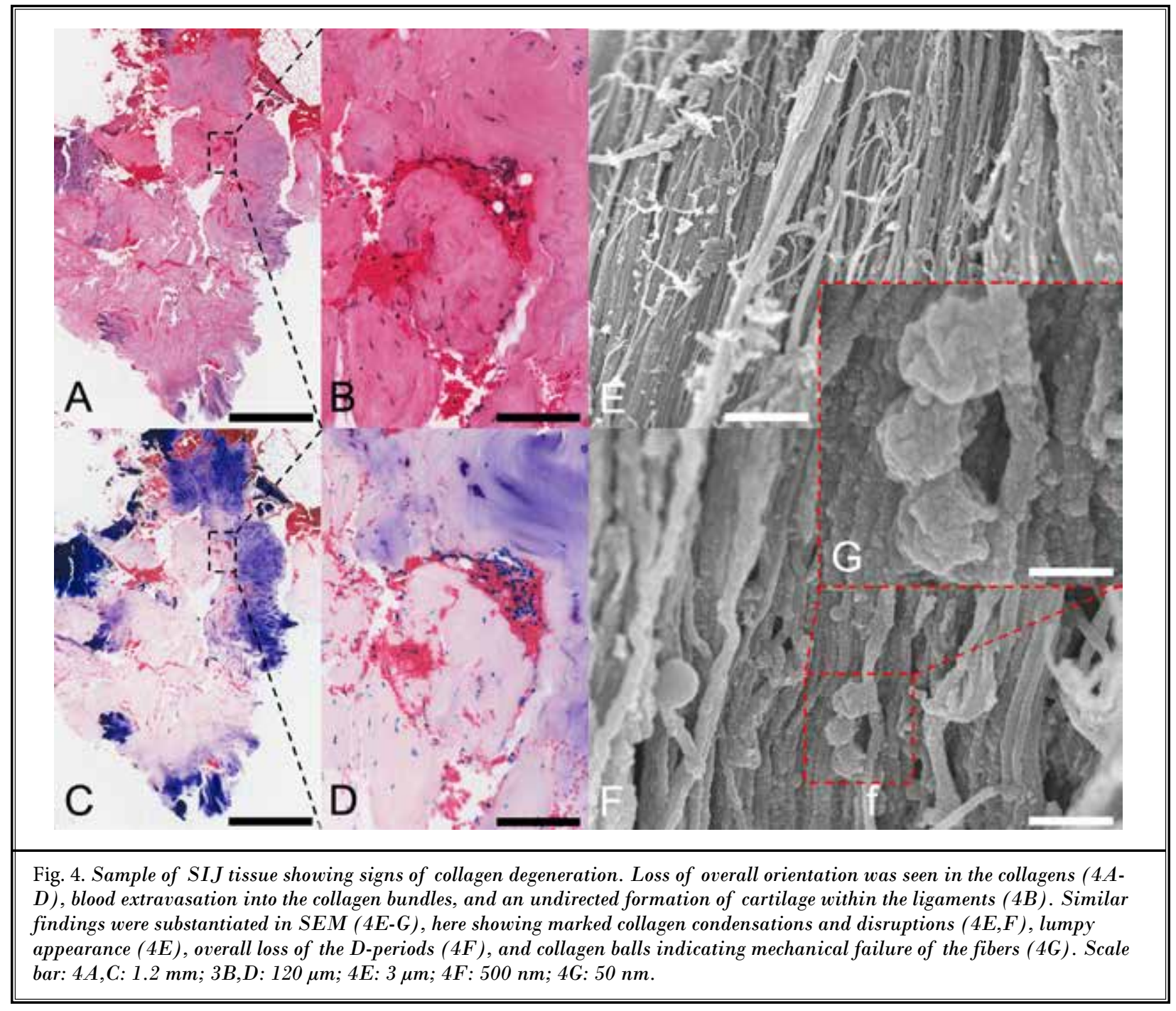

cartilage roughening, and fibrillation are perceived as normal in the SIJ in the course of ageing $(32-35,51)$. Also, there is consensus that the characteristics of osteoarthritis for other synovial joints might not necessarily apply to the SIJ in light of the functional adaptations $(15,28,34,51)$ this joint has, as the change in loading during the course of upright posture makes this joint unique.

However, to date, the given changes have largely been limited to the hard tissues, whereas the study on the morphology of the SIJ ligaments in patients with pain originating from this area was hampered by the limited surgical accessibility, and has been unproven as to whether any changes occur to the SIJ ligaments in this pathology. The ligaments are known to be densely innervated from the L4 and L5 segments (16,55-61), with direct branches of the dorsal and ventral rami of the lumbosacral plexus $(4,58,61-63)$, as well as the obturator (63) and the superior gluteal nerve $(4,62)$. Predominantly, the S1 and S2 nerve roots appear to contribute, being situated between the interosseous and posterior SIJ ligaments $(16,48)$. These nerve fibers are housed between the ligaments and the existence of substance $P$, calcitonin gene-related peptide, and tyrosine hydroxylase might be one potential source for sustained SIJ pain (56). This evident spatial and functional relationship further underlines the importance of elucidating the pathology of the SIJ ligaments. To our knowledge, this given report provides for the first time morphologic evidence into mechanical failure of 


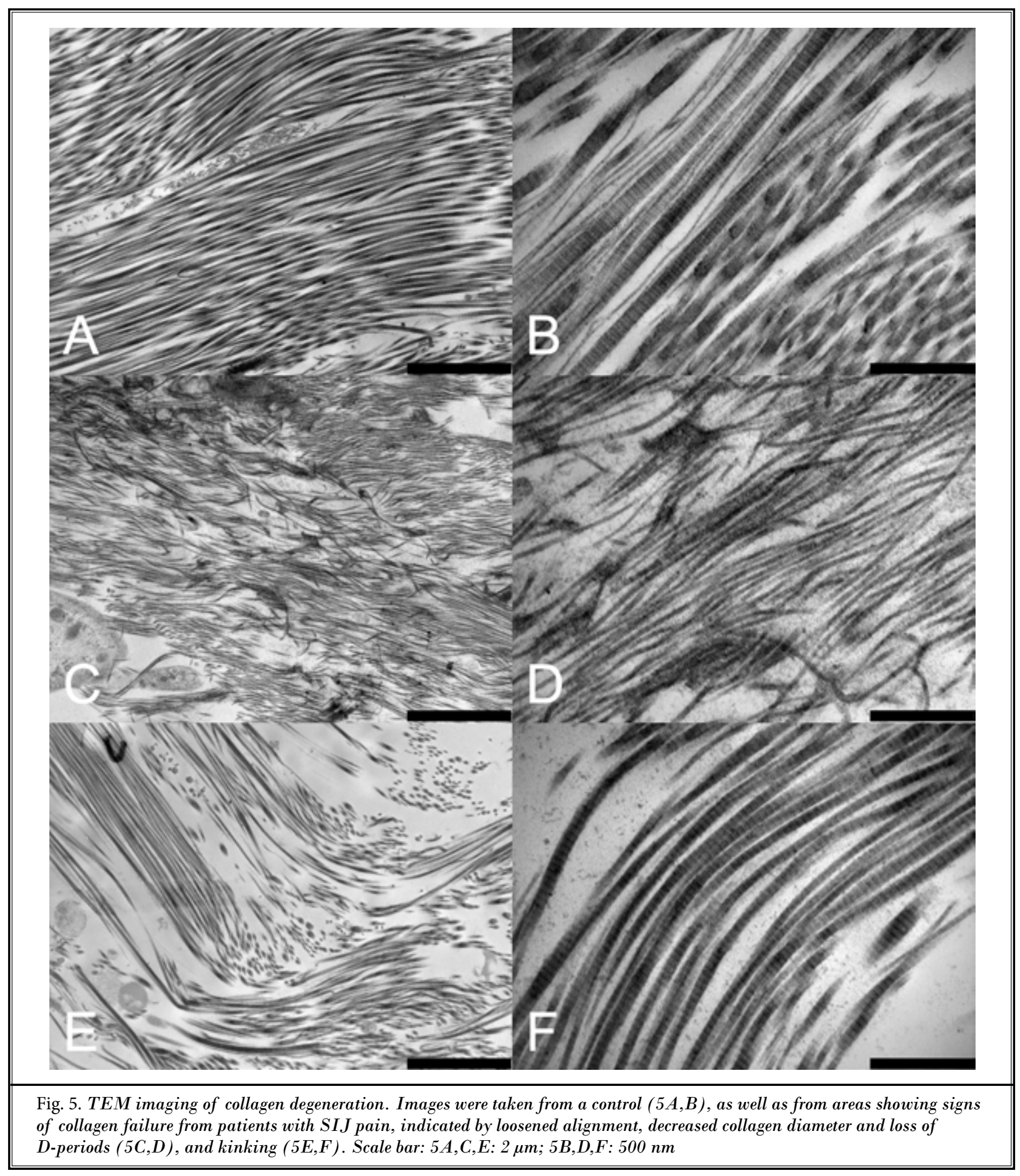

ligaments without making attempt to clarify the etiology of these observations; this is vastly limited to clinical studies and beyond the scope of this work.

\section{Limitations}

The given explorative study has a number of limitations: only a few samples were included, and because of this small number harvested from women with SIJ 
pathology exclusively, no relations to pain duration, age, or gender could be described at a level allowing to correlate these findings. Further to this, no cartilage has been included in the assessment, although it has been described anecdotally that SIJ pathology might be related to cartilage degeneration. However, potential of this proposed postsurgical assessment lies in the evaluation of ligament degeneration, substantiating SIJ pathology and relating it to major load-bearing structures. Future studies will need to substantiate these findings and relate them to mid- and long-term patient outcomes. It would further be desirable that obtaining the tissues would always be carried out by the same surgeon. Although this has been done by experts here, it would help further standardize the given approach of tissue retrieval.

\section{Conclusions}

With the given surgical method of posterior distraction arthrodesis (8), it was, to our knowledge, for the first time possible to assess the morphology of the SIJ ligaments with diagnostically confirmed pain, and to investigate these tissues in detail with particular focus on the collagens being part of the formed matrix.
CT- and MRI-based methods have so far failed to give evidence on potential changes of the ligamentous apparatus $(35,64)$, with the exceptions of traumatic disruption (22-24) and spondyloarthropathy (17-21). A similar study had used CT-guided aspirates from the SIJ, showing comparable high sensitivity and specificity for the diagnosis of SIJ-related pathology, but with clear focus on inflammation of the joint (65). In summary, compared with the structurally intact condition, a number of features were observed in ligament tissue samples from patients with chronic SIJ pain. Collagen degeneration with loss of collagen integrity and loss of orientation and chondrification is significantly different between patients with SIJ pathology and agematched controls. These findings may serve as an indicator of mechanical failure of the ligaments in patients with SIJ pain.

\section{Acknowledgments}

The authors would like to thank Elizabeth Girvan, Sharon Lequeux, Allan Mitchell, and Professor Gabriela Aust for their help regarding the electron microscopy. Glynny Kieser proofread the manuscript as a native English speaker.

\section{REFERENCES}

1. Cohen SP, Chen Y, Neufeld NJ. Sacroiliac joint pain: A comprehensive review of epidemiology, diagnosis and treatment. Expert Rev Neurother 2013; 13:99-116.

2. Szadek KM, van der Wurff P, van Tulder MW, Zuurmond WW, Perez RS. Diagnostic validity of criteria for sacroiliac joint pain: A systematic review. J Pain 2009; 10:354-368.

3. Fortin JD. Sacroiliac joint dysfunction: A new perspective. J Back Musculoskelet Rehabil 1993; 3:31-43.

4. Fortin JD, Kissling RO, O'Connor BL, Vilensky JA. Sacroiliac joint innervation and pain. Am J Orthop (Belle Mead, NJ) 1999; 28:687-690.

5. Laplante BL, Ketchum JM, Saullo TR, DePalma MJ. Multivariable analysis of the relationship between pain referral patterns and the source of chronic low back pain. Pain Physician 2012; 15:171-178.

6. Kim JT, Rudolf LM, Glaser JA. Outcome of percutaneous sacroiliac joint fixation with porous plasma-coated triangular titanium implants: An independent re- view. Open Orthop J 2013; 7:51-56.

Cher DJ, Reckling WC, Capobianco RA. Implant survivorship analysis after minimally invasive sacroiliac joint fusion using the iFuse Implant System. Med Devices (Auckl) 2015; 8:485-492.

8. Fuchs $V$, Ruhl B. Distraction arthrodesis of the sacroiliac joint: 2-year results of a descriptive prospective multi-center cohort study in 171 patients. Eur Spine J 2018; 27:194-204.

9. Rudolf L, Capobianco R. Five-year clinical and radiographic outcomes after minimally invasive sacroiliac joint fusion using triangular implants. Open Orthop J 2014; 8:375-383.

10. Stark DD, McCarthy SM, Filly RA, Parer JT, Hricak H, Callen PW. Pelvimetry by magnetic resonance imaging. AJR AM J Roentgenol 1985; 144:947-950.

11. Cheng J, Chen SL, Zimmerman N, Dalton JE, LaSalle G, Rosenquist R. A new radiofrequency ablation procedure to treat sacroiliac joint pain. Pain Physician 2016; 19:603-615.
12. Karaman H, Kavak GO, Tufek A, et al. Cooled radiofrequency application for treatment of sacroiliac joint pain. Acta Neurochir (Wien) 2011; 153:1461-1468.

13. Rimmalapudi VK, Kumar S. Lumbar radiofrequency rhizotomy in patients with chronic low back pain increases the diagnosis of sacroiliac joint dysfunction in subsequent follow-up visits. Pain Res Manag 2017; 2017:4830142.

14. Tinnirello A, Barbieri S, Todeschini M, Marchesini M. Conventional (Simplicity III) and cooled (SInergy) radiofrequency for sacroiliac joint denervation: Oneyear retrospective study comparing two devices. Pain Med 2017; 18:1731-1744.

15. Vleeming A, Schuenke MD, Masi AT, Carreiro JE, Danneels L, Willard FH. The sacroiliac joint: An overview of its anatomy, function and potential clinical implications. J Anat 2012; 221:537-567.

16. Roberts SL, Burnham RS, Ravichandiran K, Agur AM, Loh EY. Cadaveric study of sacroiliac joint innervation: Implications for diagnostic blocks and radiofrequen- 
cy ablation. Reg Anesth Pain Med 2014; 39:456-464.

17. Melchior J, Azraq Y, Chary-Valckenaere I, et al. Radiography, abdominal CT and MRI compared with sacroiliac joint CT in diagnosis of structural sacroiliitis. Eur J Radiol 2017; 95:169-176.

18. Baraliakos $X$, Braun J. Imaging scoring methods in axial spondyloarthritis. Rheum Dis Clin North Am 2016; 42:663678.

19. Diekhoff T, Hermann KG, Greese J, et al. Comparison of MRI with radiography for detecting structural lesions of the sacroiliac joint using $\mathrm{CT}$ as standard of reference: Results from the SIMACT study. Ann Rheum Dis 2017; 76:15021508.

20. Maksymowych WP. Imaging in axial spondyloarthritis: Evaluation of inflammatory and structural changes. Rheum Dis Clin North Am 2016; 42:645-662.

21. Zejden A, Jurik AG. Anatomy of the sacroiliac joints in children and adolescents by computed tomography. Pediatr Rheumatol Online J 2017; 15:82.

22. Burgess AR, Eastridge BJ, Young JW, et al. Pelvic ring disruptions: Effective classification system and treatment protocols. J Trauma 1990; 30:848-856.

23. Doro CJ, Forward DP, Kim H, et al. Does $2.5 \mathrm{~cm}$ of symphyseal widening differentiate anteroposterior compression I from anteroposterior compression II pelvic ring injuries? J Orthop Trauma 2010; 24:610-615.

24. Gill JR, Murphy C, Quansah B, Carrothers A. Management of the open book APC II pelvis: Survey results from pelvic and acetabular surgeons in the United Kingdom. J Orthop 2017; 14:530-536.

25. Soisson O, Lube J, Germano A, et al. Pelvic belt effects on pelvic morphometry, muscle activity and body balance in patients with sacroiliac joint dysfunction. Plos One 2015; 10:e0116739.

26. Fick RA. Handbuch der Anatomie und Mechanik der Gelenke unter Bercksichtigung der bewegenden Muskeln. Jena, Germany: Gustav Fischer; 1904.

27. Gerlach UJ, Lierse W. Functional construction of the sacroiliac ligamentous apparatus. Acta Anat (Basel) 1992; 144:97102.

28. Kapandji IA. Funktionelle Anatomie der Gelenke: Schematisierte und kommentierte Zeichnungen zur menschlichen Biomechanik; einbändige Ausgabe-Obere Extremität, untere Extremität, Rumpf und
Wirbelsäule. 5th ed. Stuttgart, New York: Thieme; 2009.

29. Weisl $\mathrm{H}$. The movements of the sacroiliac joint. Acta Anat (Basel) 1955; 23:80-91.

30. Vleeming A, Stoeckart R, Volkers AC, Snijders C). Relation between form and function in the sacroiliac joint. Part I: Clinical anatomical aspects. Spine 1990; 15:130-132.

31. Vleeming A, Volkers AC, Snijders C), Stoeckart R. Relation between form and function in the sacroiliac joint. Part II: Biomechanical aspects. Spine 1990; 15:133-136.

32. Eno JJ, Boone CR, Bellino MJ, Bishop JA. The prevalence of sacroiliac joint degeneration in asymptomatic adults. J Bone Joint Surg Am 2015; 97:932-936.

33. Kampen WU, Tillmann B. Age-related changes in the articular cartilage of human sacroiliac joint. Anat Embryol 1998; 198:505-513.

34. Klang E, Lidar M, Lidar Z, Aharoni D, Eshed I. Prevalence and awareness of sacroiliac joint alterations on lumbar spine $\mathrm{CT}$ in low back pain patients younger than 40 years. Acta Radiol 2017; 58:449455.

35. Puhakka KB, Melsen F, Jurik AG, Boel LW, Vesterby A, Egund N. MR imaging of the normal sacroiliac joint with correlation to histology. Skeletal Radiol 2004; 33:15-28.

36. Panjabi MM. The stabilizing system of the spine. Part I. Function, dysfunction, adaptation, and enhancement. J Spine Disord 1992; 5:383-389.

37. Panjabi MM. The stabilizing system of the spine. Part II. Neutral zone and instability hypothesis. J Spinal Disord 1992; 5:390-397.

38. Stark J, Fuentes J, Fuentes T, Idemmili C. The history of sacroiliac joint arthrodesis: A critical review and introduction of a new technique. Curr Orthop Pract 2011; 22:545-557.

39. Schleifenbaum S, Prietzel T, Aust G, et al. Acellularization-induced changes in tensile properties are organ specific: An in-vitro mechanical and structural analysis of porcine soft tissues. PloS One 2016; 11:e0151223.

40. Scholze $M$, Singh A, Lozano PF, et al. Utilization of $3 \mathrm{D}$ printing technology to facilitate and standardize soft tissue testing. Sci Rep 2018; 8:11340.

41. Rappoport LH, Luna IY, Joshua G. Minimally invasive sacroiliac joint fusion using a novel hydroxyapatite-coated screw: Preliminary 1-year clinical and radiographic results of a 2-year prospective study. World Neurosurg 2017; 101:493-497.

42. Hammer N, Möbius R, Schleifenbaum $S$, et al. Correction: Pelvic belt effects on health outcomes and functional parameters of patients with sacroiliac joint pain. PloS One 2015; 10:e014009o.

43. Hammer N, Möbius R, Schleifenbaum $S$, et al. Pelvic belt effects on health outcomes and functional parameters of patients with sacroiliac joint pain. PloS One 2015; 10:e0136375.

44. Mens JMA, Damen L, Snijders CJ, Stam HJ. The mechanical effect of a pelvic belt in patients with pregnancy-related pelvic pain. Clin Biomech (Bristol, Avon) 2006; 21:122-127.

45. Dussault RG, Kaplan PA, Anderson MW. Fluoroscopy-guided sacroiliac joint injections. Radiology 2000; 214:273-277.

46. Jee H, Lee JH, Park KD, Ahn J, Park Y. Ultrasound-guided versus fluoroscopy-guided sacroiliac joint intra-articular injections in the noninflammatory sacroiliac joint dysfunction: A prospective, randomized, single-blinded study. Arch Phys Med Rehabil 2014; 95:330-337.

47. Kasliwal PJ, Kasliwal S. Fluoroscopyguided sacroiliac joint injection: Description of a modified technique. Pain Physician 2016; 19: E329-338.

48. Robinson TJ, Roberts SL, Burnham RS, Loh E, Agur AM. Sacro-iliac joint sensory block and radiofrequency ablation: Assessment of bony landmarks relevant for image-guided procedures. Biomed Res Int 2016; 2016:1432074.

49. Chakrabortty S, Kumar S, Gupta D, Rudraraju S. Intractable sacroiliac joint pain treated with peripheral nerve field stimulation. J Anaesthesiol Clin Pharmacol 2016; 32:392-394.

50. Patil AA, Otto D, Raikar S. Peripheral nerve field stimulation for sacroiliac joint pain. Neuromodulation 2014; 17:98101.

51. Schunke GB. The anatomy and development of the sacro-iliac joint in man. Anat Record (Hoboken) 1938; 72:313-332.

52. Rosatelli AL, Agur AM, Chhaya S. Anatomy of the interosseous region of the sacroiliac joint. J Orthop Sports Phys Ther 2006; 36:200-208.

53. Weisl $\mathrm{H}$. The ligaments of the sacro-iliac joint examined with particular reference to their function. Acta Anat (Basel) 1954; 20:201-213. 
54. Egund N, Jurik AG. Anatomy and histology of the sacroiliac joints. Semin Musculoskelet Radiol 2014; 18:332-339.

55. Cox M, Ng G, Mashriqi F, et al. Innervation of the anterior sacroiliac joint. World Neurosurg 2017; 107:750-752.

56. Szadek KM, Hoogland PV, Zuurmond WW, deLange JJ, Perez RS. Nociceptive nerve fibers in the sacroiliac joint in humans. Reg Anesth Pain Med 2008; 33:3643.

57. Szadek KM, Hoogland PV, Zuurmond WW, deLange J), Perez RS. Possible nociceptive structures in the sacroiliac joint cartilage: An immunohistochemical study. Clin Anat 2010; 23:192-198.

58. Ikeda R. [Innervation of the sacroili- ac joint. Macroscopical and histological studies]. Nihon Ika Daigaku Zasshi 1991; 58:587-596.

59. Forst SL, Wheeler MT, Fortin JD, Vilensky JA. The sacroiliac joint: Anatomy, physiology and clinical significance. Pain Physician 2006; 9:61-67.

6o. Vilensky JA, O'Connor BL, Fortin JD, et al. Histologic analysis of neural elements in the human sacroiliac joint. Spine 2002; 27:1202-1207.

61. Waikakul S, Chandraphak S, Sangthongsil P. Anatomy of $\mathrm{L}_{4}$ to $\mathrm{S}_{3}$ nerve roots. J Orthop Surg (Hong Kong) 2010; 18:352-355.

62. Fortin JD, Washington WJ, Falco FJ.
Three pathways between the sacroiliac joint and neural structures. AJNR Am J Neuroradiol 1999; 20:1429-1434.

63. Grob KR, Neuhuber WL, Kissling RO. Die Innervation des Sacroiliacalgelenkes beim Menschen. Z Rheumatol 1995; 54:117-122.

64. Attias N, Arzani S, Duncan G, Taber KH, Hayman LA. Sectional imaging anatomy: Pelvic ring ligaments. J Comput Assist Tomogr 2001; 25:975-979.

65. Knipp D, Simeone FJ, Nelson SB, Huang AJ, Chang CY. Percutaneous CT-guided sacroiliac joint sampling for infection: aspiration, biopsy, and technique. Skeletal Radiol 2018; 47:473-482. 
